Brit. J. industr. Med., 1951, 8, 244.

\title{
"ENTENTE RADIOLOGIQUE"
}

\section{A STEP TOWARDS INTERNATIONAL AGREEMENT ON THE CLASSIFICATION OF RADIOGRAPHS IN PNEUMOCONIOSIS}

BY

\author{
A. L. COCHRANE, I. DAVIES, and C. M. FLETCHER
}

From the Pneumoconiosis Research Unit of the Medical Research Council, Llandough Hospital, Nr. Cardiff

Advance in our present understanding of the natural history of pneumoconiosis and of our knowledge of its prevalence in various dusty occupations can only be achieved if workers in different countries and within each country can reach some agreement on radiological diagnosis and classification.

For this purpose the following requirements must be met.

There must be an agreed system of description and classification of the radiological appearances.

Different observers must be able to apply the system of classification thus agreed in such a way that they will classify a given series of radiographs into the same categories. Fletcher and Oldham (1949 and 1951) have shown that agreement in the use of a radiological classification of pneumoconiosis cannot be achieved without taking special measures. To reduce inter-observer error they suggested both the use of standard films and also a system of duplicate consultative readings.

The radiographs used by different observers must be of a uniform and high technical standard. Results obtained by the use of miniature radiographs cannot be compared with the results obtained by full size films (Schepers, 1950 ; Fletcher, 1951). Even with full-size films, technical differences will result in considerable differences in classification (Fletcher and Oldham, 1949). It is essential that where comparisons are to be made between the prevalence of disease in two different populations, the radiological technique used should be the same throughout both populations.

In this paper we shall describe recent attempts we have made to achieve some degree of international agreement on a system of radiological classification for the pneumoconioses. The work is still in progress, and this is in the nature of an interim report which may encourage observers other than those already concerned to join in the field of agreement.

In 1949, there was serious divergence among the methods adopted by different workers in Europe for the radiological classification of pneumoconiosis. In Great Britain, the classification proposed by Davies and Mann (1949), and by Fletcher, Mann, Davies, Cochrane, Gilson and Hugh-Jones (1949) was superseding that proposed by Hart and Aslett (1942), and was becoming generally accepted. This classification distinguished " simple" and "complicated "pneumoconiosis, and the sub-divisions of the former were based predominantly on the profusion and diffusion rather than on the size or type of opacity in radiographs. In France and Belgium (van Mechelen, 1950) on the other hand, classifications similar to that proposed by Eck and Hanaut (1944) were generally used. These classifications were based chiefly on the character of the abnormal opacities. Linear, micronodular, and nodular types were separated without regard for the number or profusion of the opacities. The word " reticulation" was used in many countries to imply anything from the earliest to the most advanced abnormality found in pneumoconiosis, in the absence of coalescent shadows.

In Germany (Böhme, 1934 ; Jötten and Gärtner, 1947); Switzerland (Schinz and Eggenschwyler, 1947 ; Lang, 1948); Holland (Mey, 1947); and the U.S.S.R. (Genkin and Molokanov, 1950) classifications based on that recommended by the 1930 international conference on silicosis were used, the disease being divided into three stages, which were separated partly on radiological, and partly on clinical grounds. In Italy (Vigliani, Parmeggiani, and Zanetti, 1948 ; Vigliani, 1950) reticular, early and late nodular, and massive stages were described.

The three-stage classification was also commonly 
used in the United States of America (Jones, 1942), but the Public Health Service (Dreesen, Page, Hough, Trasko, Jones, and Franks, 1942) employed a more elaborate system based on the report of the Pancoast Committee (U.S. Public Health Service, 1935). Compromise classifications were also suggested (Garland, 1936). The Japanese (Yamamoto, 1951) also used three stages. In Australia (Outhred, 1949 ; George and Wallman, 1949) increased linear markings or reticulation, early or nodular pneumoconiosis, and well developed pneumoconiosis were described.

South African workers continued to use the system published by the Miners' Phthisis Medical Bureau in 1936. This separated "simple" and " infective" silicosis, and recognized eight different stages of the simple disease, ranging from increased linear markings to large mottling.

This account of existing forms of radiological classification is far from comprehensive, but it gives some idea of the extent of international confusion which existed when, in February, 1950, the International Labour Office held a conference of experts on pneumoconiosis in Sydney. This conference had the question of radiological classification of pneumoconiosis on its agenda. It finally accepted by a majority vote a scheme of classification, given in full in Appendix 2. It will be seen that it is similar to that proposed by the Pneumoconiosis Research Unit of the Medical Research Council (Fletcher and others, 1949), in that it recognizes a broad distinction between films with only disseminated, more or less circular opacities, and those with coalescent or massive shadows, and it bases the sub-division of the simple or nodular forms of pneumoconiosis on the profusion and diffusion of the opacities rather than on their size, while leaving room for sub-divisions according to their size or other characteristics.

In the summer of 1950 we wished to compare the prevalence of pneumoconiosis in certain British coal mines at which we had carried out surveys, with the reported prevalence at coal mines in the North of France (Declercq, Balgaires, Flouquet, and Morel, 1949). We therefore suggested a joint study of the classification of radiographs between workers in South Wales and in the North of France. In August, 1950, two of us (A.L.C. and I.D.) visited Douai taking 200 films of South Wales coal miners which had already been classified according to the P.R.U. scheme. These films were then classified by Drs. Balgaires, Aupetit, Declercq, Foubert, Jarry, and Nadiras in Douai according to their system of classification, while a group of films which they had already classified by their method was read by Drs. Cochrane and Davies. The two classifications applied to these groups of films were then compared, and it became clear that they were similar in important respects. There was, for example, almost complete correspondence between the British and international categories B, C, and D of massive fibrosis and the French "pseudo-tumorales", and also between the category $A$ of early massive fibrosis and the French category of " confluence".

On the other hand, the classification of the films which the British called "simple pneumoconiosis" was quite different. The French classified these films, according to the dominant morphological type and size of the opacities, as " pinhead ", micronodular, and nodular; the British paid attention chiefly to their profusion and recognized lesser degrees of abnormality than the French, who read the British category 1 films as normal, reticulation or fibrotique. The approximate equivalents of the two classifications are given in the extreme left hand and right hand columns of Table 1. After some discussion, it was agreed that for a trial period, the

\section{TABLE 1}

APPROXIMATE EQUIVALENT OF BRITISH, INTERNATIONAL, ANGLO-FRENCH, AND FRENCH RADIOLOGICAL CLASSIFICATION OF PNEUMOCONIOSIS

\begin{tabular}{|c|c|c|c|}
\hline $\begin{array}{c}\text { British } \\
\text { (P.R.U.) }\end{array}$ & $\begin{array}{l}\text { International } \\
\text { (I.L.O.) }\end{array}$ & Anglo-French & French \\
\hline 0 & 0 & 0 & $\mathrm{~N}^{*}$ \\
\hline 1 & 1 & 1 & $\mathbf{R}$ or $\mathrm{F}$ \\
\hline 2 & 2 & $\begin{array}{c}\stackrel{P}{M} \\
\mathrm{~N}\end{array}$ & \multirow{3}{*}{$\begin{array}{l}\text { Pinhead } \\
\text { Micronodulaire } \\
\text { Nodulaire }\end{array}$} \\
\hline 3 & \multirow{2}{*}{3} & \multirow{2}{*}{$3 \stackrel{P}{\mathrm{M}}$} & \\
\hline \multirow[t]{2}{*}{4} & & & \\
\hline & $\mathrm{X}$ & $X$ & \\
\hline A & A & $\underset{n}{\mathrm{p}}$ & $\mathrm{C}$ \\
\hline$\stackrel{\mathrm{B}}{\mathrm{C}}$ & $\stackrel{\mathrm{B}}{\mathrm{C}}$ & $\stackrel{\mathrm{B}}{\mathrm{C}}$ & \multirow{2}{*}{$\mathrm{T}$} \\
\hline D & D & D & \\
\hline & & & $\begin{array}{l}\mathbf{N}=\text { normale } \\
\mathbf{R}=\text { reticulation } \\
\mathbf{F}=\text { fibrotique } \\
\mathbf{C} \text { = coalescence } \\
\mathbf{T}=\text { tumorale }\end{array}$ \\
\hline
\end{tabular}

French workers would try to use the British numerical classification as well as their own, and that the British would in turn sub-divide their categories 2 and 3 according to the morphological type of 
opacity, category 1 presenting too little abnormality for this sub-division.

During the autumn of 1950 , both sets of workers adopted this joint method. In December, 1950, a group of films which had been thus classified by Dr. Cochrane and Dr. Davies was selected with the following approximate distribution of categories according to the British numerical classification :

$\begin{array}{llll}\text { Category 0 } & \ldots & \ldots & \text { 25 films } \\ \text { Category 1 } & \ldots & . & 25 \text { films } \\ \text { Category 2 } & \ldots & . & 60 \text { films } \\ \text { Category 3 } & \ldots & \ldots & 60 \text { films } \\ \text { Category A } & \ldots & . . & 30 \text { films }\end{array}$

These films were sent to Douai and were read by Dr. Balgaires and his colleagues according to the joint classification. Both groups of workers read the films on two separate occasions, so that some measure of the consistency of reading could be obtained. In Fig. 1 a comparison is given between the first British and the first French reading on this set of films according to the British numerical classification and according to the French morphological classification. It will be seen that there was agreement on approximately $60 \%$ of the films. On the whole, the French tended to allot lower category numbers to the films (i.e. to read less abnormality) than the British. For example, 58 films were called category 2 by the British ; 25 of these were given a lower category by the French and only eight were given a higher category. They tended to read the nodular types with much greater frequency than the British, reading pinhead less often. The extreme divergences shown in Fig. 1a were chiefly due to films read by the British as category A, being considered by the French to show tuberculosis without clear evidence of underlying pneumoconiosis (five cases) or with only very slight changes.

The British read the films according to the numerical category on two occasions with $80 \%$ consistency, while the French, with less experience of this method, achieved $70 \%$ consistency. In the morphological classification of films with category 2 or more abnormality, the French were $82 \%$ consistent, while the British, who placed $77 \%$ of the films into the micronodular group, were thus able to achieve $87 \%$ consistency.

It was clear that while both groups of readers were using the classification consistently, there were still considerable differences in the readings of the two groups.

In January, 1951, two of us (A.L.C. and C.M.F.) again went to Douai and read the set of films in consultation with Dr. Balgaires and his colleagues. Dr. A. Hanaut, chief medical officer to the Charbonnages de France, also took part in this consultative reading. As a result, a final system of classification incorporating the essential features of both British and French systems was agreed. This is given in summary in Table 1 showing the equivalent classification of categories according to the

Fig. I.

\section{COMPARISON OF FRENCH AND BRITISH INDEPENDENT READINGS}

\section{(a) NUMERICAL CLASSIFICATION}

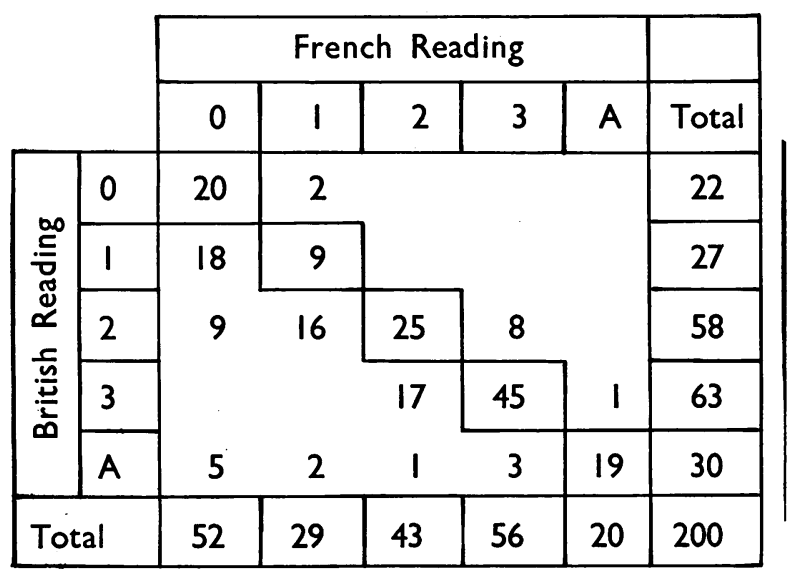

(b) MORPHOLOGICAL CLASSIFICATION

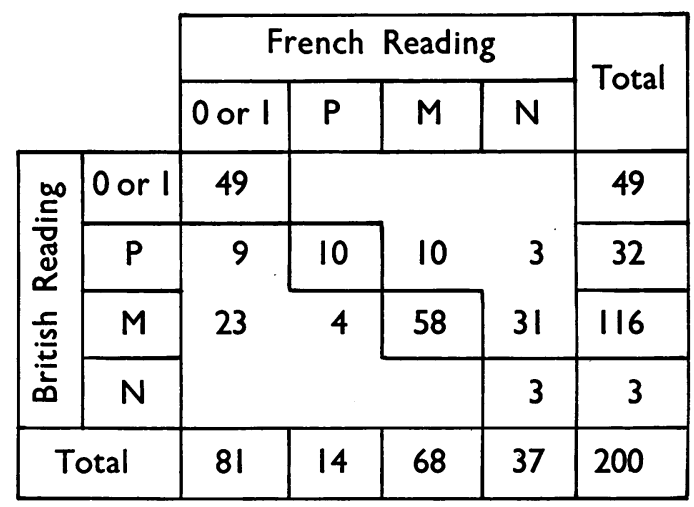

In this figure and in Figs. 2 and 3 the numbers are the numbers of films given the classification in the corresponding row and column headings. Thus the diagonal squares show the number of films upon which the readings were in agreement. 
original British, French, and the international classification. The full details of the Anglo-French system of classification is given in Appendix 1 .

It will be seen that this Anglo-French classification is very similar to the international classification suggested by the conference of the International Labour Organisation at Sydney in 1950 (Appendix 2).

The final Anglo-French classification differed from the earlier joint classification in adding a category $\mathrm{X}$ for abnormal films in which the diagnosis of pneumoconiosis was doubtful, and also in allowing for doubt (expressed by " ?") in classifying the underlying morphological type of pneumoconiosis in cases with extensive confluence.

The Anglo-French differs from the international classification chiefly in that it makes formal provision for classifying the morphological type of appearance into three particular types. The use of category $\mathrm{X}$ is also slightly different. Other minor differences lie in the definitions of category 1 and of categories A-D, but these are differences of phrase rather than of essence. It was agreed that the classification could only be fully appreciated by studying illustrative films, rather than by the use of verbal descriptions in isolation.

In Fig. 2, a comparison is given between the French independent reading of the group of films and the final consultative reading, and in Fig. 3 between the British independent reading and the consultative reading. A full comparison is given in section $a$ of each figure; and sections $b$ and $c$ give an analysis according to the classification on the numerical basis and on the morphological basis. It will be seen that relative to the consultative reading, the French, working by themselves, still tended to give a rather lower numerical classification to the films than the British, and tended to read the nodular type more frequently. The British numerical classification was fairly close to the final agreed classification with a tendency to allot slightly higher category numbers and with a tendency to read pinhead rather more frequently and nodular much less frequently.

It has been noted (Fig. 1a) that there were five films considered by the British to show category A, but which the French had diagnosed as $\mathrm{O}$. This was because they considered these films to show tuberculous shadows rather than confluence. Of these films, four were finally agreed to show simple pneumoconiosis with tuberculous scars, and one was put into category $\mathrm{X}$ indicating that the appearances might not have been due to pneumoconiosis at all. The other films placed in category $X$ were four which had been read as category 2 by the British and one read as category 1 . These were films showing a dense reticular pattern without any clear-cut opacities characteristic of pneumoconiosis. Category $\mathrm{X}$ was found to be very useful for these relatively infrequent films whose interpretation is difficult, but it was agreed that this category should only be used sparingly. It was also interesting that the films placed in category $\mathrm{X}$ were all of elderly ex-miners.

It should also be noted in the agreed reading that of the 135 films allocated a category number of 2, 3 or $\mathrm{A}$ and thus receiving a morphological reading, 108 , or $80 \%$, were read as micronodular (Fig. 2c and 3c). Pinhead films formed only $12 \%$ of the total, and nodular only $8 \%$. It thus appears that, at any rate in films of South Wales coal miners, the morphological classification is not very discriminating.

In our discussion concerning the relative importance of the numerical classification according to the profusion of the opacities and the classification according to the type and size of the opacities, the French experts pointed out that in progression of simple pneumoconiosis, there is both an increase in size and number of opacities, as had indeed been found by Davies, Fletcher, Mann, and Stewart (1949), and that confluence leading to massive fibrosis is more likely to occur in films of the nodular type so that the morphological classification

TABLE 2

PERCENTAGE FREQUENCY OF DIFFERENT MORPHOLOGICAL TYPES OF FILMS ACCORDING TO CATEGORY NUMBER FRENCH READING

\begin{tabular}{|c|c|c|c|c|}
\hline \multirow{2}{*}{ Category } & \multicolumn{3}{|c|}{ Morphological Type } & \multirow{2}{*}{ Tota } \\
\hline & $\mathbf{P}$ & $\mathbf{M}$ & $\mathbf{N}$ & \\
\hline 2 & $\begin{array}{c}9 \\
(4)^{*}\end{array}$ & $\begin{array}{c}63 \\
(27)\end{array}$ & $\begin{array}{c}28 \\
(12)\end{array}$ & $\begin{array}{l}100 \\
(43)\end{array}$ \\
\hline 3 & $\begin{array}{l}16 \\
(9)\end{array}$ & $\begin{array}{c}63 \\
(35)\end{array}$ & $\begin{array}{c}21 \\
(12)\end{array}$ & $\begin{array}{l}100 \\
(56)\end{array}$ \\
\hline A & $\begin{array}{c}5 \\
(1)\end{array}$ & $\begin{array}{l}30 \\
(6)\end{array}$ & $\begin{array}{c}65 \\
(13)\end{array}$ & $\begin{array}{l}100 \\
(20)\end{array}$ \\
\hline
\end{tabular}

AGREED READING

\begin{tabular}{|c|c|c|c|c|c|}
\hline \multirow{2}{*}{ Category } & \multicolumn{4}{|c|}{ Morphological Type } & \multirow{2}{*}{ Total } \\
\hline & $\mathbf{P}$ & $\mathbf{M}$ & $\mathbf{N}$ & ? & \\
\hline 2 & $\begin{array}{l}16 \\
(9)\end{array}$ & $\begin{array}{c}80 \\
(43)\end{array}$ & $\begin{array}{c}4 \\
(2)\end{array}$ & - & $\begin{array}{l}100 \\
(54)\end{array}$ \\
\hline 3 & $\begin{array}{c}8 \\
(5)\end{array}$ & $\begin{array}{c}82 \\
(48)\end{array}$ & $\begin{array}{c}10 \\
(6)\end{array}$ & - & $\begin{array}{c}100 \\
(59)\end{array}$ \\
\hline A & $\begin{array}{c}7 \\
(2)\end{array}$ & $\begin{array}{c}61 \\
(17)\end{array}$ & $\begin{array}{c}11 \\
\text { (3) }\end{array}$ & $\begin{array}{l}21 \\
(6)\end{array}$ & $\begin{array}{c}100 \\
(28)\end{array}$ \\
\hline
\end{tabular}

* Actual number in brackets. 
corresponds to the progression of the disease and gives an indication of prognosis.

In Table 2, the morphological classification of all the films placed in categories 2,3 , and A according to the independent French reading and according to the agreed reading is given. It will be seen that in the agreed reading there is no significant difference in the distribution of the three types of opacity in the different numerical categories, although in the French reading the nodular type was read more frequently in category A films. This difference is partly due to the fact that in six of the films of category A which the French readers described as nodular, it was ultimately agreed that the nodular appearance was part of the confluent shadow and that the underlying morphological type was not classifiable. They were therefore described as A? (Fig. 2). It is known (Gough, 1947) that, pathologically, massive fibrosis begins by the formation of collagenous nodules larger than those found in simple pneumoconiosis. These nodules coalesce to form areas of massive fibrosis. This preliminary nodular stage of massive fibrosis may, in radiographs, be mistaken for the nodular type of simple pneumoconiosis. This mistake would naturally lead to the conclusion that there was a special tendency for the nodular type of film to go on to confluence. This confusion may be avoided by recognizing that localized nodular shadows, especially in the upper zones, are usually a sign of early massive fibrosis and that only generalized nodular appearances should be classified as simple pneumoconiosis of the nodular type.

Further studies are required to show whether the classification into pinhead, micronodular, and nodular types has important prognostic or diagnostic significance. It is probable, for instance, that workers exposed to dust with a high silica content are more likely to develop the nodular type of picture.

On the other hand, there is good evidence that the numerical classification is well related to the natural progression of the disease and is of some prognostic importance.

Progression studies carried out by the Pneumoconiosis Research Unit have shown that as the disease progresses, the classification tends to rise from 1 to 2 to 3 although the type of films, i.e. pinhead, micronodular, or nodular, nearly always remains the same. Moreover, in surveys carried out at various mines we have found that as the prevalence of pneumoconiosis increases, so does the frequency of the higher category numbers.

Massive fibrosis has not yet been seen developing in cases of category 1 , and it usually appears on a background of the upper limit of category 2 or category 3 (Davies and others, 1949 ; Cochrane, Fletcher, Gilson, and Hugh-Jones, 1951). Thus the category number has prognostic value.

Against the numerical classification it may be objected that the division of the lung fields into vertical thirds is arbitrary and is unrelated to any anatomical conception. Further, it is known from pathological studies that simple pneumoconiosis is generalized throughout both lung fields from the outset and does not start near the hilum and extend outwards in the course of time.

However, in radiographs the opacities are nearly always first seen in the centre of the lung fields and only appear in profusion more peripherally as the disease develops. This is probably due simply to the fact that at the periphery of the lung fields, as they appear in a radiograph film, the rays have had a smaller thickness of lung to traverse before reaching the film. Generalized radio-opaque foci must therefore appear less profuse in the peripheral part of the lung fields.

Thus, the definition of the categories according to the profusion at the periphery has some anatomical basis, but it is important to stress that the fundamental distinction between categories 1,2 , and 3 is based on the general profusion of opacities and not only on their diffusion to the periphery. This is one reason why standard films as well as verbal descriptions are essential to enable different observers to agree on the numerical classification of films (see below).

It must be remembered that the classification is based chiefly on experience with radiographs of coal miners who seldom develop unmodified silicosis. The opacities in classical silicosis commonly first appear and may remain confined to the upper zones. In such cases, the provision made in the international classification should be applied, i.e. " in cases where there is an uneven distribution of the opacities in different parts of the lung fields, the category is determined by the most advanced abnormality that is present over at least half of the lung field".

A meeting was held at Douai in June, 1951, at which this joint Anglo-French classification was presented to doctors concerned with coal-worker's pneumoconiosis from other coalfields in France, from Belgium and from Holland, and at which it was agreed to give the joint classification a trial over a much wider area (Aupetit, Balgaires, Declercq, Foubert, and Nadiras, 1951).

It is important to stress that the existence of an agreed classification does not ensure that the classification will be used in exactly the same way by different observers, as is seen by the disparity which existed between the British and French readings 
Fig. 2.

COMPARISON BETWEEN INDEPENDENT (FRENCH) READING AND AGREED CONSULTATIVE READING

(a) FULL COMPARISON

Agreed Reading

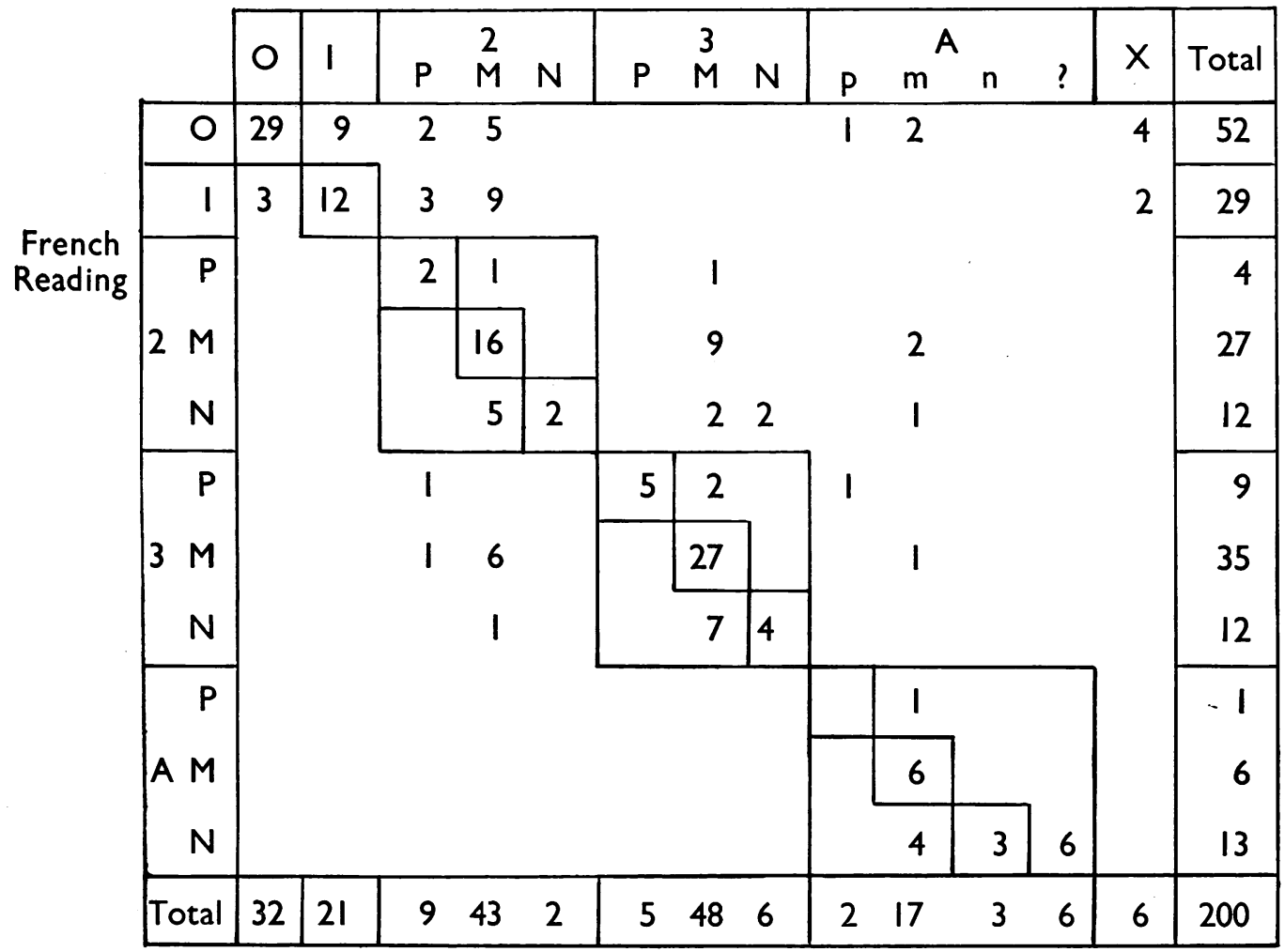

(b) COMPARISON OF

NUMERICAL CLASSIFICATION

Agreed Reading

French

\begin{tabular}{|c|c|ccccc|c|}
\cline { 2 - 8 } $\begin{array}{c}\text { Reading } \\
\text { Rench }\end{array}$ & 0 & 1 & 2 & 3 & A & $\times$ & Total \\
\hline 0 & 29 & 9 & 7 & & 3 & 4 & 52 \\
1 & 3 & 12 & 12 & & & 2 & 29 \\
2 & & & 26 & 14 & 3 & & 43 \\
3 & & & 9 & 45 & 2 & & 56 \\
A & & & & & 20 & & 20 \\
\hline Total & 32 & 21 & 54 & 59 & 28 & 6 & 200 \\
\hline
\end{tabular}

(c) COMPARISON OF MORPHOLOGICAL CLASSIFICATION Agreed Reading

\begin{tabular}{|c|c|c|c|c|c|c|}
\hline $\begin{array}{l}\text { French } \\
\text { Reading }\end{array}$ & $0+1$ & $P$ & $M$ & $N$ & $?+X$ & Tota \\
\hline $0+1$ & 53 & 6 & 16 & & 6 & 81 \\
\hline$P$ & & 9 & 5 & & & 14 \\
\hline$M$ & & 1 & 67 & & & 68 \\
\hline $\mathrm{N}$ & & & 20 & 11 & 6 & 37 \\
\hline Total & 53 & 16 & 108 & 11 & 12 & 200 \\
\hline
\end{tabular}


Fig. 3.

COMPARISON BETWEEN INDEPENDENT (BRITISH) READING AND AGREED CONSULTATIVE READING

(a) FULL COMPARISON

Agreed Reading

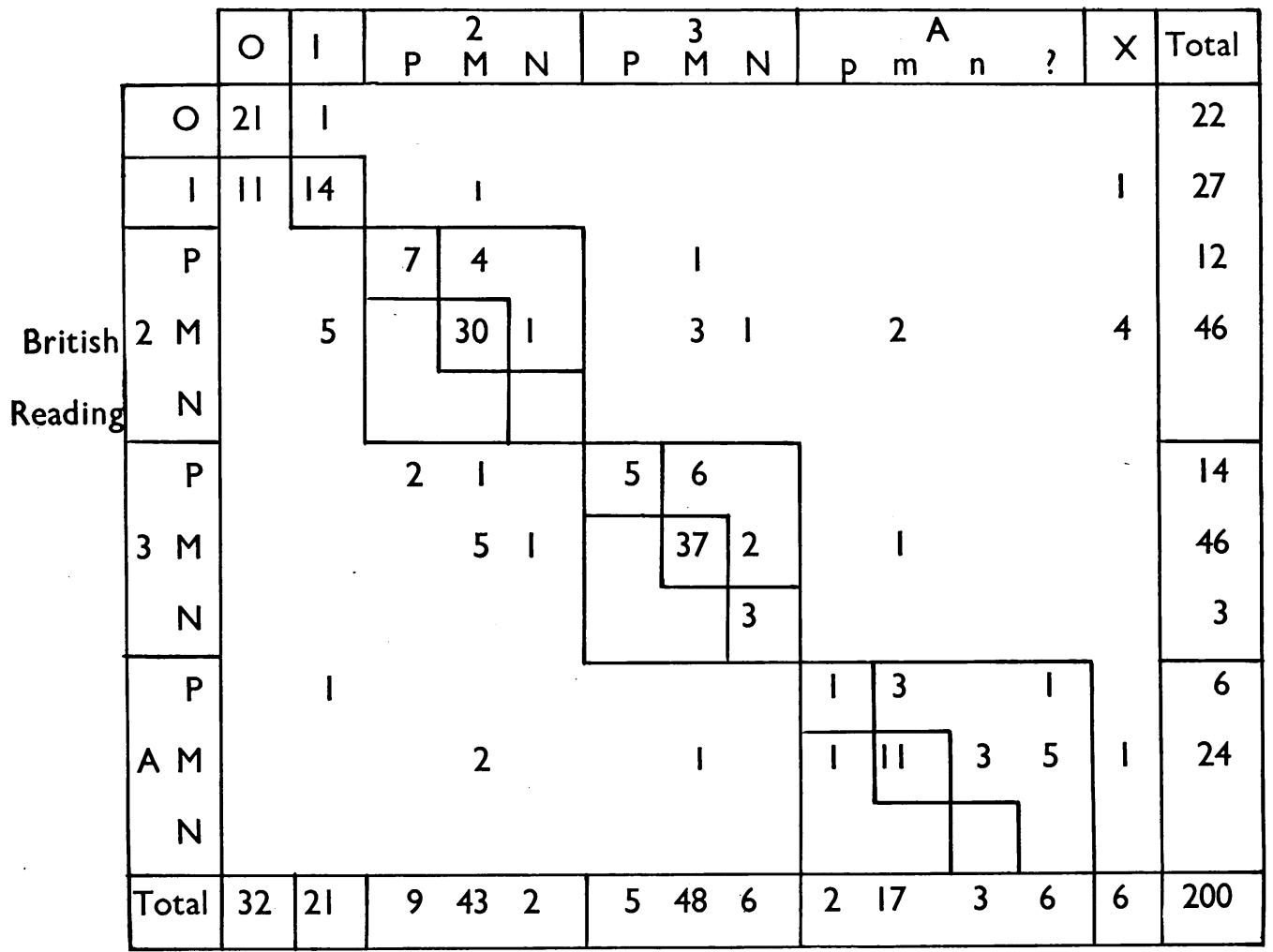

(b) COMPARISON OF

NUMERICAL CLASSIFICATION Agreed Reading

British

\begin{tabular}{|c|c|ccccc|c|}
\cline { 2 - 6 } Reading & 0 & 1 & 2 & 3 & A & X & Total \\
\hline 0 & 21 & 1 & & & & & 22 \\
1 & 11 & 14 & 1 & & & 1 & 27 \\
2 & & 5 & 42 & 5 & 2 & 4 & 58 \\
3 & & & 9 & 53 & 1 & & 63 \\
A & & 1 & 2 & 1 & 25 & 1 & 30 \\
\hline Total & 32 & 21 & 54 & 59 & 28 & 6 & 200 \\
\hline
\end{tabular}

(c) COMPARISON OF MORPHOLOGICAL CLASSIFICATION Agreed Reading

\begin{tabular}{|c|c|c|c|c|c|c|}
\hline \multirow{2}{*}{$\begin{array}{l}\text { British } \\
\text { Reading }\end{array}$} & \multirow{2}{*}{$0+1$} & & \multirow[b]{2}{*}{$N$} & \multirow[b]{2}{*}{$?+X$} & \multirow[b]{2}{*}{ Total } \\
\hline & & $P$ & $M$ & & & \\
\hline $0+1$ & 47 & & 1 & & 1 & 49 \\
\hline$P$ & I & 15 & 15 & & 1 & 32 \\
\hline M & 5 & I & 92 & 8 & 10 & 116 \\
\hline $\mathrm{N}$ & & & & 3 & & 3 \\
\hline Total & 53 & 16 & 108 & II & 12 & 200 \\
\hline
\end{tabular}


before the joint meeting. It is suggested that, in order to ensure that a classification of this kind is used in the same sense by different observers, it will be necessary to have a set of films, such as the 200 used in our consultative reading at Douai, with an agreed classification. This could be sent to different workers who could classify the films according to their own interpretation of the classification, and then compare their results with the agreed opinion. In this way they will be able to ensure that they are using the classification appropriately. The International Labour Office would be a suitable body to collect and hold such a set of films. Joint consultative readings between workers from different centres would do much to facilitate general agreement.

Fletcher and Oldham (1951) have shown that the use of standard films may enable observers who are inexperienced in a particular classification to give the same readings as those given by more experienced observers. A set of standard films appropriate to the joint classification has been collected at Cardiff and Douai. A limited number of sets of films as agreed by the Pneumoconiosis Research Unit are available on application to the Director of the Pneumoconiosis Research Unit, Llandough Hospital, near Cardiff. Both British and French standard films may be consulted on application to Cardiff or to Dr. Balgaires, 20 Rue des Minimes, Douai (Nord), France.

One important difficulty remains to be resolved, and that is the distinction between localized shadows due to active or inactive tuberculosis, and those due to the early stages of massive fibrosis (category A). Mann (1951) claimed to be able to distinguish these two types of radiological appearance, but many other observers have found difficulty in this differentiation, and we have found serious interobserver error in the interpretation of these early localized shadows. Mention has already been made of the disagreement between the British and French independent readings in such cases. It is our present practice to read all localized shadows upon a background of category 2 or 3 simple pneumoconiosis as category A unless the appearances are quite characteristic of healed inactive tuberculosis, and this is the procedure that we recommend. Further investigation, especially by follow-up studies, will be necessary before this difficulty can be resolved.

\section{Summary}

As a first step towards solving the problem of the existing international disagreement concerning the classification of radiographs in pneumoconiosis an attempt was made to compare a classification used in the northern coalfields of France with that used by the Pneumoconiosis Research Unit in Great Britain, the latter classification being very similar to that proposed by the International Labour Office international conference on pneumoconiosis at Sydney in 1950 .

A large number of films were read in consultation between British readers and French readers. As a result, a provisional joint classification was achieved. This classification was used on a further group of films, and after a second joint consultation a final agreed classification embodying the essential features of both systems was reached.

This classification is given in detail (Appendix 1). It is similar to the international classification (Appendix 2), but makes formal provision for the description of morphological types of simple pneumoconiosis.

At a meeting of mine medical officers and others at Douai in June, 1951, it was agreed to give the classification a trial in various centres in France, Belgium, and Holland.

To ensure the accurate use of this classification, standard films exemplifying the categories have been selected and are kept at Cardiff in Great Britain and at Douai in France. It is suggested that it will also be necessary to have a group of films which have been classified according to the agreed method which could be sent to other workers to be read by them to ensure that they are using the classification correctly.

\section{REFERENCES}

Aupetit, J., Balg aires, E., Declercq, G., Foubert, J. J., and Nadiras, P. (1951). Rev. med. min. In the press.

Böhme, A. (1933). Beitr. Klin. Tuberk. 84, 119.

Cochrane, A. L., Fletcher, C. M., Gilson, J. C., Hugh-Jones, P. (1951). British Journal of Industrial Medicine, 8, 53

Davies, I., Fletcher, C. M., Mann, K. J., and Stewart, A. (1949). Proc. 9th Int. Congr. on Industr. Med., London, 1948, p. 773. and Mann, K. J. (1949). Ibid., p. 768.

Declercq, G., Balgaires, E., Flouquet, M., and Morel, A. (1949). Rev. méd. min., 2 , 9 .

Dreesen, W. C., Page, R. T., Hough, J. W., Trasko, V. M., Jones, J. L., and Franks, R. W. (1942). Publ. Hlth Bull., Wash., No. 277

Eck, M., and Hanaut, A. (1944). Arch. Mal. prof., 6, 74.

Fletcher, C. M. (1951). Brux.- méd. To be published.

-, Mann, K. J., Davies, I., Cochrane, A. L., Gilson, J. C., and Hugh-Jones, P. (1949). J. Fac. Radiol., i, 40.

and Oldham, P. D. (1949). British Journal of Industrial Medicine, 6, 168.

-

Garland, L. H. (1936). Radiology, 27, 21.

Genkin, S. M., and Molokanov, K. P. (1950). Sovetsk. Med., No. 6, p. 24.

George, W. E., and Wallman, L. S. (1949). A Medical Examination of the Employees of the Coal Mining Industry of New South Wales. Sydney, 1949. Gough, J. (1947). Occup. med., 4, 86.
Hart, P. d'A., and Aslett, E. A. (1942). Spec. Rep. Ser. med. Res. Coun., Lond., No. 243.

Jones, R. H. (1942). J. Amer. med. Ass., 119, 611.

Jötten, K. W., and Gärtner, H. (1947). Dtsch. med. Wschr., 72, 531 . 
Lang, F. (1948). Arztl. Mh., 10, 909.

Mann, K. J. (1951). Thorax, 6, 43.

Mechelen, V. van (1950). "Quelques Données sur l'état Actuel du Problème de l'Anthraco-Silicose." Institut d'Hygiène des Mines, Hasselt.

Mey, A. (1947). Mededeelingen van den Geneeskundigen Dienst van de Nederlandsche Steenkolenmijnen, No. 1

Miners' Phthisis Medical Bureau (1936). Report for the three years ended July, 1935. Pretoria, p. 15.

Outhred, K. G. (1949). Med. J. Aust., 2, 355.
Schepers, G. W. H. (1750). Co.fference on Silicosis and Aluminium Therapy, January, 1)50. McIntyre Research Foundation. Toronto, p. 48.

Schinz, H. R., Eggenschwyler, H. (1947). Vischr. Naturf. Ges, Zürich., 3, 119.

U.S. Public Health Service (1935). Publ. Hlth Rep., Wash., 50, 989. Vigliani, E. C. (1950). "Lo Stato Attuale della Silicosi in Italia." Geneva:

-, Parmeggiani, L., and Zanetti, E. (1948). Med. d. Lavoro, 39, 1. Yamamoto, M. (1951). Arch. industr. Hyg. occup. Med., 3, 339.

\section{A P P E N D I X 1}

\section{PROPOSED ANGLO-FRENCH CLASSIFICATION OF RADIOGRAPHS IN PNEUMOCONIOSIS}

The classification only concerns those common and well recognized kinds of pneumoconiosis that give rise to the appearance of bilateral, discrete, more or less circular opacities in radiographs of the chest, e.g. silicosis, coalworker's pneumoconiosis, etc.

At present, the classification is based solely on radiographic appearances such as may be seen in a full size postero-anterior or antero-posterior chest radiograph of a satisfactory technical standard taken in inspiration. It is not intended to define pathological entities, or to define stages of disease for compensation.

It is obvious that such a classification must be severely limited. It must be simple and flexible, and it must allow for the use of generally recognized symbols which may be easily codified. The proposed classification is based on previous classifications, particularly the French system of Eck and Hanaut. the British system of the Pneumoconiosis Research Unit, and the international system proposed at Sydney in February, 1950.

From the point of view of the radiographic diagnosis of pneumoconiosis, the system recognizes two main groups of appearance: first, normal and abnormal (not necessarily pneumoconiotic); and secondly, specific appearances of pneumoconiosis.

Normal or not Necessarily Pneumoconiotic Appearances

Normal but not necessarily pneumoconiotic appearances are indicated by the letters $\mathbf{O}$ and $X$. $O$ indicates normal films without any sign of pneumoconiosis. $\mathrm{X}$ indicates films showing shadows which are usually symmetrical, linear or circular in form, which may suggest pneumoconiosis but which are more likely to be due to other pathological conditions.

\section{Appearances of Pneumoconiosis}

Two main subdivisions are distinguished. They are (I) simple pneumoconiosis (P.R.U.), or images ombres fines (French), or pneumoconiosis with discrete opacities (I.L.O.) ; (II) progressive massive fibrosis (P.R.U.), ombres étendues (French), pneumoconiosis with coalescent or massive shadows (I.L.O.).

Simple Pneumoconiosis.-These films are denoted by numerals 1, 2, and 3 indicating the profusion of the opacities. In the case of categories 2 and 3, the letters $P$, $\mathbf{M}$, and $\mathbf{N}$ are added to indicate the dominant morphological type of the opacities.

1. Abnormal films characterized by the presence of a small number of minute, more or less circular, opacities extending over not more than half of the medial twothirds of the lung fields.

2. More numerous opacities extending over more than half of the medial two-thirds of the lung fields, but which are sparse or absent in the lateral third.

3. Profuse opacities distributed through the whole of both lung fields including the outer third.

$\mathbf{P}$ (pinhead) denotes opacities ranging in size from the limit of visibility to $1.5 \mathrm{~mm}$. in diameter giving rise to profuse and uniform granularity.

M (micronodular) denotes more or less circular opacities ranging in diameter from 1.5 to $3 \mathrm{~mm}$.

$\mathrm{N}$ (nodular) denotes discrete, more or less circular opacities, larger than $3 \mathrm{~mm}$. in diameter.

Examples of pinhead, micronodular, and nodular films are given in Fig. 4.

The categories of the classification will be indicated in the following way :-

$$
\begin{aligned}
& 2 \mathrm{P}, 2 \mathrm{M}, 2 \mathrm{~N} \text {, } \\
& 3 \mathrm{P}, 3 \mathrm{M}, 3 \mathrm{~N} \text {, }
\end{aligned}
$$

The opacities in category 1 are too sparse to be categorized in the types $\mathbf{P}, \mathbf{M}$, and $\mathrm{N}$.

Progressive Massive Fibrosis.-These films comprise two main groups : coalescent shadows are indicated by the letter $A$, and massive shadows (equivalent to the French ombres pseudo-tumorales) designated by letters B, C, and D.

A. Shadows occupying at least one anterior rib space, generally formed by the coalescence of more or less circular shadows more than $1.0 \mathrm{~cm}$. in diameter with indefinite margins and of uneven density. Next to the letter $\mathrm{A}$, one can add the small letters $\mathrm{p}, \mathrm{m}, \mathrm{n}$, in order to indicate the dominant type of the radiological appearance upon which the lesions have developed. If the underlying appearance is impossible to describe, the letter A is followed by a "?".

Example : Ap, Am, A?.

B. Dense shadows which are more extensive, better defined and of more homogeneous density which extend over less than three anterior rib spaces.

C. The same type of shadow extending over more than three anterior rib spaces.

D. The letter D indicates that one of the preceding class of shadows is associated with serious distortion of the pulmonary architecture.

The classification only takes account of the predominant type of appearance. In cases of mixed appearance, the most advanced is codified, and when there is asymmetry, the most seriously affected side is codified.

This classification requires in addition to verbal descriptions, a set of standard films which has been established at Douai and at Cardiff. 


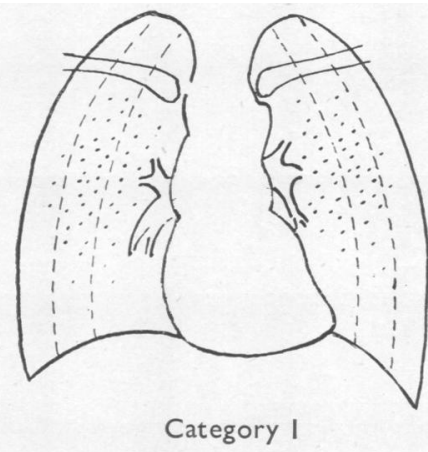

Category I

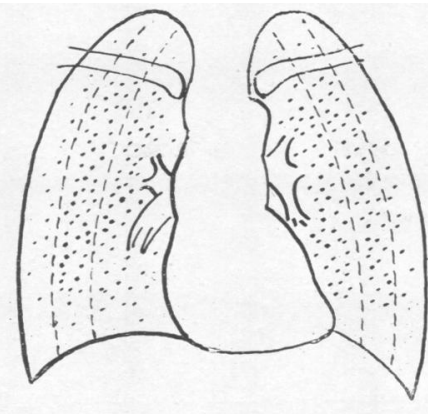

Category 2

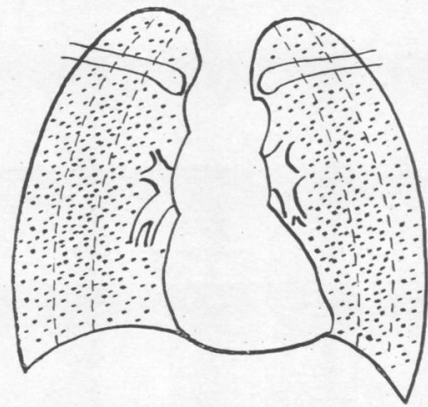

Category 3

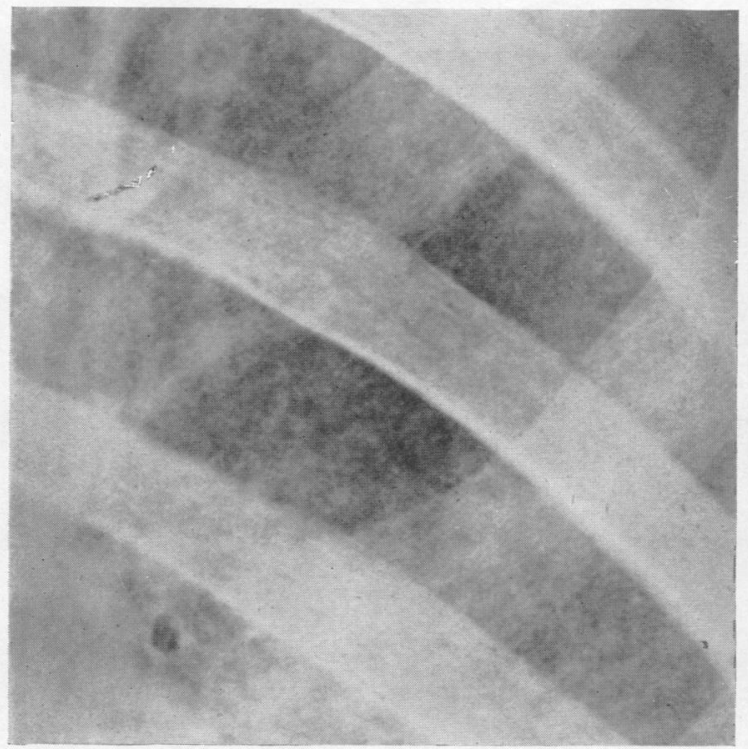

Pinhead

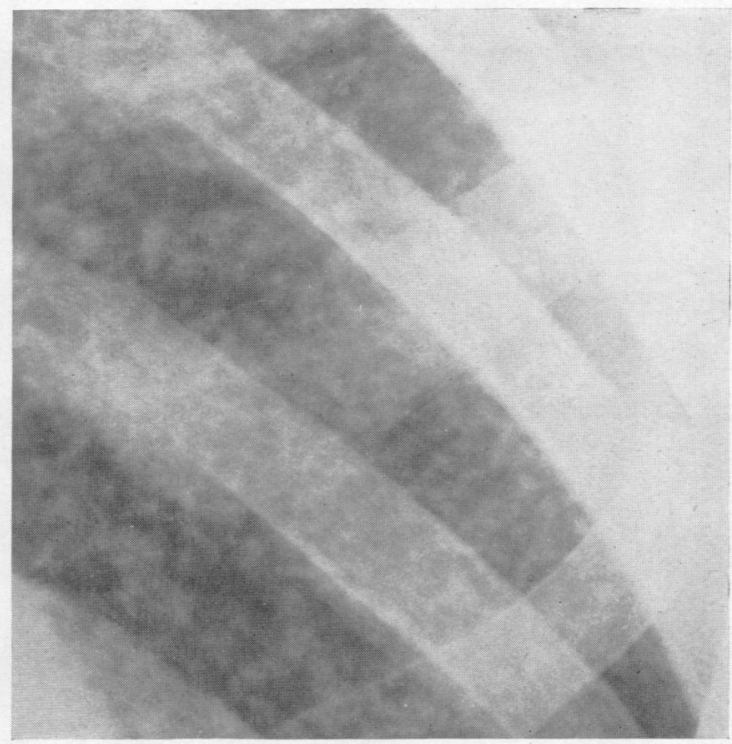

Micronodular

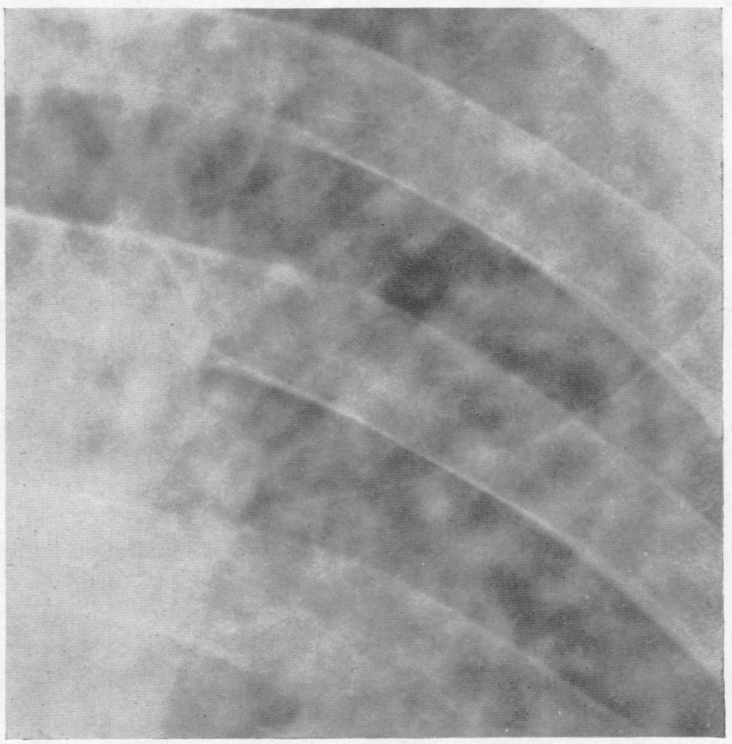

Nodular

Fig. 4.-Reproduction of the left mid zone of French standard films illustrating pinhead, micronodular, and nodular types. 
CODING OF THE ANGLO-FRENCH CLASSIFICATION

\begin{tabular}{l|l|l}
\hline $\begin{array}{l}\text { Appearances not due to pneumo- } \\
\text { coniosis } \\
\text { Images non pneumoconiotiques }\end{array}$ & O \\
\hline & $\begin{array}{l}\text { Simple pneumoconiosis, or } \\
\text { ombres fines, or } \\
\text { pneumoconiosis with discrete opacities }\end{array}$ & $\begin{array}{l}1 \\
2 \mathrm{P}, 2 \mathrm{M}, 2 \mathrm{~N} \\
\mathbf{3}, 3 \mathrm{M}, 3 \mathrm{~N}\end{array}$ \\
\cline { 2 - 3 } $\begin{array}{l}\text { Appearances of pneumoconiosis } \\
\text { Images pneumoconiotiques }\end{array}$ & $\begin{array}{l}\text { Progressive massive fibrosis, or } \\
\text { ombres étendues, or } \\
\text { pneumoconiosis with } \\
\text { coalescent or massive shadows }\end{array}$ & $\begin{array}{l}\mathrm{Ap}, \mathrm{Am}, \mathrm{An}, \mathrm{A} \text { ? } \\
\mathrm{C} \\
\mathrm{D}\end{array}$ \\
\hline
\end{tabular}

\section{A P P E E N D I X 2 \\ SUGGESTED INTERNATIONAL SCHEME FOR THE CLASSIFICATION OF RADIOGRAPHS* IN SOME OF THE PNEUMOCONIOSES}

This classification is proposed for the purpose of promoting clarity and mutual understanding between scientists concerned with the study of pneumoconiosis. It has no relation to the legal definition of stages of pneumoconiosis for compensation.

\section{Principles}

The classification only concerns those common and well recognized kinds of pneumoconiosis that give rise to the appearance of bilateral, discrete, more or less circular opacities in radiographs of the chest, e.g. in silicosis, coalworker's pneumoconiosis, etc.

At present the classification is based solely on radiographic appearances such as may be seen in a full size P.A. or A.P. chest radiograph of a satisfactory technical standard. It is not intended to define pathological entities.

No interpretation other than pneumoconiosis is to be admitted ; secondary conditions such as emphysema, pneumothorax, pneumonia, etc., are to be separately described if present.

No reference is to be made to such variations in radiographic appearances as may be seen in individuals without pneumoconiosis. All such appearances, in the absence of other diseases, are to be classified as "within normal limits". It is recognized that appearances such as have been described as "exaggeration of linear markings", "generalized arborization", etc., may be of clinical importance in certain industries, but their significance appears too uncertain for them to be included in a classification of radiographic appearances of pneumoconiosis.

Terms such as " initial ", “ terminal ", " progressive ", " infective" which suggest a definite process of development, or a definite pathogenesis, should not be used in describing a radiograph.

Descriptive terms applicable to various types of radiographic pattern such as " small or large mottling", " pinhead ", " micronodular", " nodular", " cobweb ",

* From the Report of the International Labour Organization's third international conference of experts on pneumoconiosis held in Sydney in 1950 .
" angel wings", "pseudotumorale", etc., may have a colloquial descriptive value, but they are not necessary, and should not be included in the basic classification. In particular, the word "reticulation" should never be used.

\section{The Classification}

A major subdivision is recognized between films showing only small, more or less circular, discrete, disseminated opacities, and those showing coalescent or massive shadows. Although there is convenience in the phrases " simple pneumoconiosis" and " complicated pneumoconiosis" to describe these two major divisions, the simplicity of the one and the presence of any special complicating condition in the other are open to too much doubt to permit the use of these terms. Thus there are two major classes of films : (1) pneumoconiosis with discrete opacities; and (2) pneumoconiosis with coalescent or massive shadows.

Within each of these two major subdivisions it is necessary to have subdivisions or categories representing increasing degrees of abnormality.

In pneumoconiosis with discrete opacities three main categories are proposed. The inaccuracies of radiographic classification are too great to permit the use of a greater number. A fourth category is suggested for those cases in which the discrete opacities are of a character that does not enable them to be included in any of the three main categories.

These categories are to be referred to by the numbers 1,2 , and 3 ; the miscellaneous group is to be referred to as $\mathrm{X}$.

In pneumoconiosis with coalescent or massive shadows the subdivisions are made on the basis of the extent and density of the coalescent or massiva shadows. An extra subdivision is made for those cases in which gross distortion of the bronchial tree and pulmonary parenchyma has occurred. These subdivisions are to be referred to by the capital letters, A, B, C, and D. In these cases, it is unnecessary to refer to the category of the pneumoconiosis upon which massive fibrosis is superimposed. 
The limits of the categories are to be defined in two ways ; first by verbal definitions as given below ; and second by standard reference films (see notes below).

The classification proposed is the following :

Radiographs Within Normal Limits

Radiographs designated 0.

Pneumoconiosis With Discrete Opacities

Radiographs Designated 1.-In these radiographs a small number of opacities may be seen in at least two anterior rib spaces extending over not more than half of the medial two-thirds of the lung fields.

Radiographs Designated 2.-In these radiographs opacities extend over more than half of the medial two-thirds of the lung fields but are sparse or absent in the lateral third.

Radiographs Designated 3.- In these radiographs profuse opacities extend over the whole of both lung fields including the lateral third, although they may be sparse or absent above the clavicles.

Radiographs Designated X.-These are radiographs with discrete opacities whose appearance does not accord with any of the preceding categories.

In cases where there is an uneven distribution of the opacities in different areas of the lung fields, the category is determined by the most advanced abnormality that is present over at least half of a lung field.

Pneumoconiosis with Coalescent or Massive Shadows Radiographs Designated A.-In these films opacities more than $1 \mathrm{~cm}$. in diameter may be seen in one or more areas, commonly coalescing, but not constituting a massive shadow of even density.

Radiographs Designated B.-In these films one or more massive shadows are present, extending over less than the equivalent of three anterior rib spaces on either side.

Radiographs Designated C.--In these films large massive shadows of uniform density extend over the equivalent of three or more anterior rib spaces on either side.
Radiographs Designated D.-In these radiographs one or more massive shadows are present associated with gross distortion of the pulmonary anatomy. The massive shadows may of themselves be such as would be classified as $\mathrm{A}, \mathrm{B}$, or $\mathrm{C}$ in the absence of such distortion.

\section{Notes}

Radiographic technique should be of the highest standard. The penetration should be such that the outline of the vertebral column, but not the intervertebral discs, may be distinguished through the heart shadow.

Radiographs should be coded simply by giving the appropriate number and letter. Descriptive terms may be used at the convenience of individual observers to qualify any category. This allows for reference to the size of opacities if this is considered important : e.g. 2. "macronodulation" ; 2. " micronodulation"; 3 . "pinhead"; 3. " nodular".

In radiographs with coalescent or massive shadows the appropriate numbers for the associated discrete opacities may also be given in brackets: e.g. (2) B, (3) A, etc.

Additional interpretation may similarly be added : e.g. (3) A. pneumothorax R. lung.

To assist in consistent classification it is suggested that standard reference radiographs exemplifying the categories should be held by some central international organization such as the I.L.O. Good reproductions of these films should be made for distribution to those wishing to use the classification.

In addition, sets of radiographs derived from cases of the commoner kinds of pneumoconiosis might be classified according to the scheme by a committee of experts and be held by the same central organization. Observers in various countries might then check their use of the scheme by seeing if their classification of these films agree with that of the committee of experts. 